\title{
Research on Ethnic Cultural Identity and Cultural Self-confidence under the Background of "Belt and Road Initiative"
}

\author{
Wenhua Yang \\ International Business School \\ Yunnan University of Finance and Economics, \\ Kunming 650221, China \\ wenhuayoung@ynufe.edu.cn
}

\author{
Jing Zhang* \\ International Business School, \\ Yunnan University of Finance and Economics, Kunming, \\ 650221, China \\ 154128175@qq.com
}

\begin{abstract}
As China's new development strategy, the "One Belt and One Road" initiative is not only the process of economic cooperation and development, but also the process of cultural absorption and diffusion. In the context of the "One Belt and One Road" initiative, cultural exchanges and economic activities between China and other countries are more frequent than ever before. This will have important theoretical and practical significance to Chinese economic and social development. It is extremely important to view its domestic culture and other countries' cultures with confidence and mature mentality for any nation, which, in turn, will further enhance cultural selfconfidence among people of this nation. Therefore, China should take the advantage of the development opportunity of "One Belt and One Road" initiative to spread Chinese ethnic culture. Chinese ethnic culture should be acted as the leading role in the process of building up culture identity for Chinese nations and other ethnic groups. Because the higher degree in the value of Chinese ethnic culture identity, the more culture confidence people will have in their own culture. Strong culture confidence is essential to build a mutual support, mutual trust united nation.
\end{abstract}

Key words - "One Belt and One Road” Initiative; cultural awareness; cultural identity; cultural self-confidence

\section{INTRODUCTION}

In September and October 2013, when Xi Jinping, the President of China, visited Central Asian and Southeast Asian countries, he proposed the major initiative to jointly build the "Silk Road Economic Zone" and the 21st century "Maritime Silk Road", hereinafter referred to as "One Belt and One Road" initiative in this paper. "One Belt and One Road" initiative was attached great importance by the international community, and got positive response and support from the countries and areas along the road. As an important strategy for China's economic reform, the conception and implementation of "One Belt and One Road" initiative is based on the integration and recognition of ethnic cultures in China's minority areas and bordering countries for thousands of years.

Ethnic culture is the totality and combination of economic, social, and historical developments in ethnic areas, including material or physical culture and spiritual culture. It exists in different forms, such as languages, religions, traditional ideas, literature, music, dances, costumes, and customs, which are different from other cultures. With the implementation of "One Belt and One Road" initiative, minority ethnic groups of people living in the bordering areas are presented with various opportunities brought about by the economic transformation and development. At the same time, their cultural developments also face many challenges.

This paper will explore the opportunities brought by the "Belt and Road" initiative to minority ethnic groups of people living in the bordering areas and the challenges they will be faced, and discuss how these ethnic minority groups of people preserve their own cultural uniqueness between ethnic culture and other cultures in the context of the "One Belt and One Road" initiative. This paper will also explore how people living along the "Belt and Road" areas should do to preserve their unique culture and further, take this opportunity to enhance the value of cultural diffusion, and to achieve cultural awareness along the minority group areas and build cultural confidence.

It is clearly stated in the report of National Development and Reform Commission of China that ethnic culture is an important part of Chinese culture [1]. Chinese culture, minority ethnic culture in particular, should make a positive response, and take advantage of the "One Belt and One Road" initiative to provide talent support and intellectual support, and constantly enhance the self-confidence in Chinese macroculture. Accordingly, the minority ethnic group people should treat other countries' cultures with a confident and scientific attitude, and actively participate in the international cultural exchange and economic cooperation and make their contribution to improve the soft power of China.

\section{CULTURE AND CULTURE IDENTITY, ETHNIC IDENTITY AND CULTURE CONFIDENCE}

\section{A. Definition of Culture}

Culture is a broad concept. Culture deals with the way people live. It is defined by anthropologists in a variety of ways--from a pattern of perceptions that influence communication to a site of contestation and conflict. The 
definition usually includes some notion of shared values, beliefs, expectations, customs, jargon, and naturals.

Winthrop thinks that anthropologist Clifford Geertz's definition of culture is traditionally the most widely one in this field. Clifford Geertz defines culture as [2]: Culture is that set of capacities which distinguishes Homo sapiens as a species and which is fundamental to its mode of adaptation; the learned, cumulative product of all social life; the distinctive patterns of thought, action, and value that characterize the members of a society or social group.

Geert Hofstede [3], the most famous social psychologist, defines culture similarly, as the programming of the mind" and the "interactive aggregate of common characteristics that influence a human group's response to its environment".

\section{B. Definition of Ethnic Identity, Culture Identity and Culture Confidence}

Carla and Reginald [4] define ethnic identity as the individual's beliefs and attitudes towards his/her own cultural group, and recognition of his/her ethnicity. This level of identity generally has four basic elements: group awareness, group attitude, group behavior, and sense of community belonging. Cultural identity refers to the cultural validation between people, between groups and between individuals and groups. Cultural identity contains the choice of values and the recognition of social consciousness. In the ethnic community, it represents the compliance with its own traditions and the group membership. It is the internal mechanism for the formation of ethnic cohesion. The term "cultural identity" in this article mainly refers to the common understanding and communication of cultures among all ethnic groups and mutual recognition and respect, as defined by Shilin Zhao and Weizhi Chen [5].

According to Zeying Wang [6], the spirit and human power is the foundation and core of culture self-confidence because culture, in its essence, is the output of human being's spiritual pursuit and creation. Ethical and spiritual confidence is the foundation as well as the energy source in the systematic structure of culture confidence. Culture confidence plays significant role in the process of culture creation and innovation and culture preservation.

Fang Liu [7] defines cultural self-confidence as a full acknowledgment of its own cultural connotation and value, and a firm belief in its own cultural characteristics and vitality. It has the following characteristics: First, respect and pride in one's own culture; second, courage and spirit in the absorption and transformation of foreign cultures; and third, respect and self-confidence in the prospect of cultural development and prosperity.

\section{The Relationship between Cultural Identity and Acculturation}

In the context of "One Belt and One Road" initiative, communication and contacts between different people and countries along the bordering countries and areas are dramatically increasing. Historical experiences indicate that very often the strong nation with confident culture become dominant compared with other cultures. Similarly, "One Belt and One Road" initiative has enhanced people's culture consciousness, cultural confidence along the "Belt and Road" countries and areas. According to Hazuda, Stern, \& Hoffnew, [8], because people do not want to abandon their past, they acculturate new ideas, values and new behavior patterns into their existing culture, which is called acculturation. In other words, acculturation is the process of adjusting and adapting to a new and different culture.

The new situation requires that we use new global technical support, with the global theory research and the observation of the cultural consciousness and cultural self improvement, to realize the symbiosis of the Chinese culture in the context of "One Belt and One Road" initiative.

There is a close relationship between cultural identity and social acculturation. Based on the research result of Berry et al. [9], integration is conducive to the cultural acculturation of ethnic minorities, however separation is not.

Whereas communication is a process, culture is the structure through which the communication is formulated and interpreted. When cultures interact, adaptation must take place for the cultures to communicate effectively. Then, it is extremely important to preserve the inheritance of the ethnic culture and enhance its value diffusion in the multicultural interactions. In the context of "One Belt and One Road" initiative, contacts and intercultural communication between heterogeneous cultures along the bordering areas will be inevitably further increased. In this process, if one's cultural is similar to that of the other nations, both nations will accept each other's culture and become acknowledged more easily.

\section{OPPORTUNITIES AND CHALLENGES OF BORDERING MinORITY AREAS AlONG THE “BELt AND RoAD” INITIATIVE}

\section{A. The Opportunities of Bordering Minority Areas along the "Belt and Road" Initiative}

The "One Belt and One Road" initiative has brought unlimited business opportunities to ethnic minority areas. There are 65 countries along the "One Belt and One Road" route, and the total population of the Silk Road Economic Belt is close to 3 billion, which constitutes a huge potential for development and a huge market place. Through the "Belt and Road Initiative," China has not only strengthened its political and economic exchanges and cooperation with countries along the route, but also has extended exchanges and cooperation in many other areas such as transportation, energy, medical care, health, science and technology, education, culture, and environmental protection. It also helps further maintain peace, security and stability in the Pacific and Indian Ocean regions.

\section{B. The Challenges brought by the "One Belt and One Road" Initiative}

With the full implementation of the "One Belt and One Road" initiative, contact, communication, and dissemination between different ethnic cultures have become inevitable. As far as the cultural development of the bordering ethnic minority areas is concerned, as new elements enter the cultural 
field, it is bound to arouse the rejuvenation of local cultural traits. Therefore, it is very important to figure out how to absorb the good culture from others as well as preserve the cultural characteristics of itself for the inheritance and development of the ethnic culture. On one hand, the local ethnic culture will be affected and changed after new cultural elements coming into the existing culture; on the other hand, keeping world peace and building a cooperative and win-win international political and economic communities will rely on the jointed efforts of all the nations instead of only one nation's effort. This suggests that besides cooperating with the bordering countries in the areas of infrastructure, international trade and investment, China should have its culture and policies recognized by nations of the bordering countries and areas. In other words, it not only requires hard power support of economic cooperation between China and countries along the Belt and Road initiative, but also requires soft power support of culture, talents and policies in China and neighboring countries along the "Belt and Road". How to use the "One Belt and One Road" initiative to widely disseminate and obtain the recognition of the ethnic culture among the others has become the key to the survival of the ethnic culture in this large cultural exchange. Among these, the diffusion of cultural values is crucial.

\section{THE INFLUENCE OF “ONE BELT AND ONE ROAD” INITIATIVE ON ETHNIC CULTURAL IDENTITY}

As a symbol different from other nationalities, ethnic culture has distinct characteristics. The specific content of diverse ethnic cultures is very unique and has "heterogeneity." At the same time, ethnic culture is shared by all members of its ethnic group. Therefore, from a transnational perspective, culture identity has emerged as some members of different countries have the same or similar ethnic culture (cultural "homogeneity").

One of the foundations for implementing the "One Belt and One Road" initiative is that China's ethnic regions and neighboring countries have a long history of cultural integration and recognition. Shaoyan Yang [10] believes that ethnic culture affects the production and development of related industries, and thus affects the content of commercial trade and the scale and pattern of commercial trade. There are both "heterogeneity" and "homogeneity" in the ethnic cultures of different regions. The "heterogeneity" of ethnic culture leads to the differentiation of products, which effectively promotes commercial trade and further creates strong competition; the advantages from the "homogeneity" of ethnic culture are conducive to the "network effect" of commercial trade, and strengthened trade relations. In the context of the "One Belt and One Road", ethnic culture has become an important force for the development of commercial trade in less developed ethnic minority areas, and it is an effective complement to economic disadvantages.

The ethnic cultural identity is conducive to the participation of bordering regions in the competition of international market economy. Cultural identity is generally more common in areas with a lot of regional cooperation in the world, such as the European Union, the North American Free Trade Area, and ASEAN, etc. Cultural cohesion is strong.
Based on the research of Rauch \& Trindade [11], Chinese ethnic network factor is estimated to account for about $60 \%$ of bilateral trade growth in the trade between countries with a large proportion of Chinese population in Southeast Asia.

The "One Belt and One Road" initiative will be beneficial to the economic development along the belt and Road countries and areas. It will also increase the influence of Chinese culture in the process of implementation of this initiative. In the 21 st century, not only economic globalization has taken place, that is, the flow of commodities, capital, etc. in the world economy, but also cultural globalization has emerged, that is, the exchange and cooperation of cultures from various countries and ethnic groups in the world. If a country or an ethnic group does not actively engage in cultural exchanges and cooperation with other countries and ethnic groups, and learn the successful experience and outstanding achievements of world culture, it will be unable to maintain the advanced nature and innovation of its own culture, and will not be able to develop fast politically, economically, and culturally. Under the background of cultural globalization, China's cultural exchanges and cooperation with countries along the "One Belt and One Road" will be more frequent, which will help improve the influence of Chinese culture.

\section{The Diffusion of VAlue Under the Heritage of ETHNIC CULTURE}

Under the background of full implementation of the "One Belt and One Road" initiative, contact and communication between heterogeneous cultures will be inevitably further increased. How to achieve the goal of preserving the unique inheritance of the ethnic culture and enhancing its value and further influence on other cultures determines the future development of an ethnic culture and even the realization of cultural self-confidence to a large extent.

How the "Belt and Road" region achieves recognition of other cultures under the circumstance of multicultural coexistence is largely related to the innovative development and cultural self-confidence of its own culture. Cultural identity is based on cultural acculturation. According to Berry [12], an international cross-cultural psychologist, individuals often show a certain attitude towards rejection or reservation in the process of adapting to heterogeneous cultures, thus forming four types of cultural acculturation patterns: integration, assimilation, separation, and marginalization. The relationship between any ethnic culture and mainstream culture exists and develops this way.

The so-called "cultural awareness" is a cultural idea that is proposed and applied in anthropological research on selfreflection and self-awareness of the ethnic culture. In the process of economic globalization and cultural integration, the "weak culture" is on the edge of being "covered" or even "is swallowed", so how to keep the ethnic culture and inherit and protect its diversity has become a common cultural challenges for ethnic groups along the "Belt and Road" to achieve ethnic cultural confidence.

In terms of its connotation, the "autonomous" cultural concept, meaning the ability to actively adapt to cultural development trends when faced with foreign cultures, and also 
the ability to minimize the impact of cultural transformation. The "self-knowledge" cultural concept means the ability to realize the necessity and importance of protecting and developing its own culture in the process of achieving cultural transformation, and is not assimilated by other ethnic cultures.

Cultural awareness is not a partial transformation of cultural concepts, values, and beliefs of individuals or certain social groups but a thorough and comprehensive selfreflection and self-recognition of their own culture. The purpose is to self-reflect and criticize their own culture, recognize its disadvantages and advantages. Only by having a clear understanding and deep reflection on their own national culture can they be able to protect their ethnic culture with purpose and consciousness when faced with foreign cultures. They will also know what traditions in their ethnic culture are outdated nowadays, and recognize the good parts in their culture which needs to be protected and developed greatly.

In conclusion, what cultural consciousness needs to achieve is the common development of various ethnic cultures and the cultivation of cultural self-confidence. This is highly consistent with the "development community" advocated by the current "Belt and Road" initiative, cultivating ethnic minorities' love for their own culture, promoting their sense of responsibility for protecting and inheriting their own culture, and ultimately realizing cultural awareness and culture selfconfidence.

\section{CONCLUSION}

There are many countries and regions along the "One Belt and One Road" route. Their geography, ethnicity, history, culture, religion and politics are various. This requires that ethnic minority group people in these areas must form the concept of cultural awareness, increase cultural selfconfidence, strengthen self-worth, protect their own culture, and strengthen the recognition of excellent traditional culture. When interacting with other cultures, the world's outstanding culture should be absorbed critically. Based on the promotion of the soft power of the ethnic culture, the minority ethnic people living in the bordering areas should establish an ethnic cultural self-confidence through value diffusion to win endorsement from others and develop its own ethnic culture. Innovation of the native culture should be encouraged while preserving the unique ethnic culture diversity. Only in this way can China realize the goal of developing economy and improving mutual communications between Chinese culture and the ethnic culture and other nations along the "Belt and Road" route.

\section{REFERENCES}

[1] National Development and Reform Commission of China., Ministry of Foreign Affairs of People's Republic of China, Ministry of Commerce of People's Republic of China. "Promoting the Silk Road Economic Belt and the 21st Century Maritime Silk Road Vision and Action", China Foreign Languages Publish Administration, vol.20, 2015.

[2] Winthrop, R.H. Dictionary of concepts in cultural anthropology. New York: Greenwood Press, 1991, p50.

[3] Hofstede, Geert. Culture's consequences. London and Beverly Hills: Sage publication, 1984 , p. 65

[4] Carla J and Reginald J. Racial identity "African self-consciousness, and career decision making in African American college women", Journal of Multicultural Counseling and Development, vol. 26(2): 1998, pp. 98-108.

[5] Shilin Zhao and Weizhi Chen. "Cultural identity and the construction of a harmonious society in frontier ethnic areas", Journal of Southwest University for Nationalities (Humanities \& Social Sciences) vol.6, 2006.

[6] Zeying Wang. "Ethical and spiritual self-confidence is the foundation and core of culture self-confidence", Ethics and Civilization, vol. 5, 2011 .

[7] Fang Liu. "Strategic considerations for cultural awareness and cultural self-confidence", Ideological and theoretical education, vol.1, 2012.

[8] Hazuda, H.P., Stern, M.P., and Hoffner, S.M. "Acculturation and assimilation among exiMcan Americans: Sales and population-based data”, Social Sciences Quarterly, 69, 1988, pp. 687-706.

[9] Berry, J.W. et al, Cross-cultural Psychology: Research and application, Cambridge: Cambridge University Press, 1999, p. 278.

[10] Shaoyan Yang. "A theoretical study of the impact of ethnic culture on international trade in the context of the "Belt and Road Initiative", Journal of Southwest University for Nationalities, vol.6, 2015.

[11] James E. Rauch and Vitor Trindade. "Ethnic Chinese networks in international trade", The Review of Economics and Statistics, vol.1, February 2002.

[12] J.W. Berry, "Acculturation: Living successfully in two cultures" International Journal of Intercultural Relations. 2005, pp. 698-715. 